\title{
Modelling metal centres, acid sites and reaction mechanisms in microporous catalysts
}

\author{
Alexander J. O'Malley, ${ }^{\text {ac }}$ A. J. Logsdail, ${ }^{\text {ab }}$ A. A. Sokol ${ }^{\mathrm{a}}$ \\ and C. R. A. Catlow *abc
}

Received 1st February 2016, Accepted 3rd February 2016

DOI: $10.1039 / c 6 f d 00010 j$

We discuss the role of QM/MM (embedded cluster) computational techniques in catalytic science, in particular their application to microporous catalysis. We describe the methodologies employed and illustrate their utility by briefly summarising work on metal centres in zeolites. We then report a detailed investigation into the behaviour of methanol at acidic sites in zeolites $\mathrm{H}-\mathrm{ZSM}-5$ and $\mathrm{H}-\mathrm{Y}$ in the context of the methanolto-hydrocarbons/olefins process. Studying key initial steps of the reaction (the adsorption and subsequent methoxylation), we probe the effect of framework topology and Brønsted acid site location on the energetics of these initial processes. We find that although methoxylation is endothermic with respect to the adsorbed

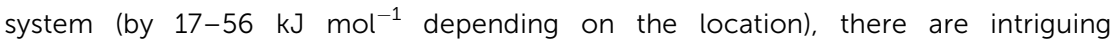
correlations between the adsorption/reaction energies and the geometries of the adsorbed species, of particular significance being the coordination of methyl hydrogens. These observations emphasise the importance of adsorbate coordination with the framework in zeolite catalysed conversions, and how this may vary with framework topology and site location, particularly suited to investigation by $Q M / M M$ techniques.

\section{Introduction}

Computational methods are now very widely used in catalytic science and are increasingly powerful in obtaining an understanding of catalysis at the molecular level, where they yield models for both the structure and mechanism that assist and complement the interpretation of experimental data. The range and scope of the field is illustrated by the recent review of their applications in zeolite catalytic science given in ref. 1 .

\footnotetext{
${ }^{a}$ Department of Chemistry, University College London, 20 Gordon St., London WC1 HOAJ, UK ${ }^{b}$ Cardiff Catalysis Institute, School of Chemistry, Cardiff University, CF10 3AT, UK

${ }^{c}$ UK Catalysis Hub, Research Complex at Harwell, Science and Technology Facilities Council Rutherford Appleton Laboratory, Harwell Science and Innovation Campus, Oxon OX11 OQX, UK
} 
The majority of contemporary computational studies in catalysis use electronic structure methods, especially Density Functional Theory (DFT) which is very widely applied, employing methods based on periodic boundary conditions (PBCs). Such methods have enjoyed considerable success and have indeed become increasingly predictive. An alternative approach is to use "QM/MM" or embedded cluster methods, which have been extensively used in computational chemistry and biomolecular sciences and in modelling localised states in solids. Such methods describe a finite region (which in the case of catalysis includes the active site, the reacting species and surrounding atoms) by a quantum mechanical method, while describing more distant regions of the solid by a more approximate method, often based on interatomic potentials. They have a number of advantages which will be discussed in greater detail in the following section; but it can be argued that they are inherently more appropriate for modelling a localised state, such as an active site on a surface or in an enzyme, as they focus the computational effort on the region containing the active site rather than the whole molecule or solid.

This paper will present recent applications of QM/MM techniques to the important and topical problem of catalytic methanol conversion in ZSM-5 and where we obtain new information on mechanistic aspects inspired by recent observations from neutron scattering studies.

In the next section we describe in greater detail the basis of the methodologies employed and illustrate briefly their application by reference to earlier studies of metal centres in zeolites. The subsequent section presents our study of methanol/ ZSM-5 which demonstrates well the power of the techniques and yields new insight into the interaction of methanol with acidic sites in zeolites.

\section{QM/MM techniques}

\section{Methodology}

In our work, we have employed a hybrid QM/MM model of zeolites developed and implemented by Paul Sherwood and colleagues ${ }^{2-6}$ in the computational quantumchemical environment software ChemShell ${ }^{7-10}$ as illustrated in Fig. 1.

The model draws on the strengths of simple molecular cluster approaches that terminate a cluster carved out of the material with hydrogen, but also accounts for steric constraints and the elastic response of the framework. The cluster is treated with an appropriate level QM method, which is chosen as a compromise between the required accuracy and available compute resources. The Chemshell zeolite model thus has much in common with alternative subtractive mechanical embedding approaches by Sauer ${ }^{\mathbf{1 1 - 1 3}}$ (implemented in QM-POT) and Morokuma ${ }^{\mathbf{1 4}}$ (ONIOM). The Chemshell methodology, however, goes beyond such schemes and provides an accurate description of the electrostatic interactions between the QM region and the framework, including polarisation and embedding effects. More recently, similar approaches (although more focused on a careful termination of the QM region with specially calibrated link atoms) have been employed, for example, by Nasluzov et al. ${ }^{15,16}$ (cov-EPE) and Sushko et al. ${ }^{17,18}$ (GUESS). The native ChemShell zeolite model briefly described in this section is complemented in Chemshell with support for both the QM-POT, cov-EPE and GUESS methods. The flexible, modular approach adopted in Chemshell extends these methodologies to other classes of material, from metal oxides to enzymes. As argued above, these 

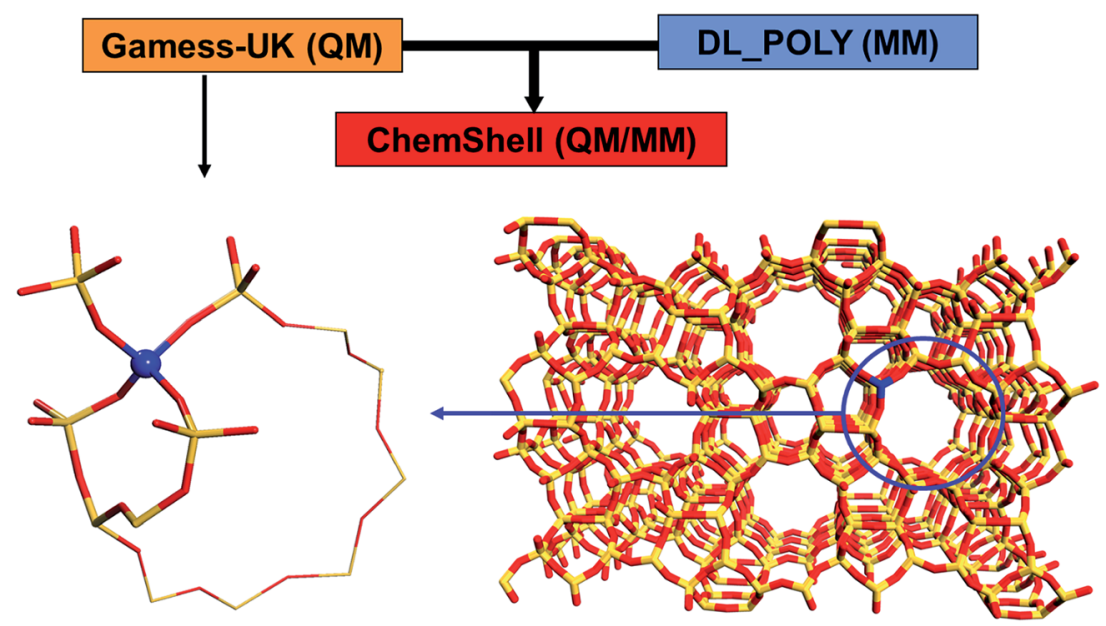

Fig. 1 ChemShell hybrid QM/MM embedded cluster diagram. A QM region incorporates a metal centre serving as an active catalytic site.

schemes serve as a computationally cheaper and at the same time chemically more accurate alternative to popular DFT PBC approaches.

To describe the long-range polarisation effects in these materials, the ChemShell model employs the Hill-Sauer molecular mechanical force-field ${ }^{19,20}$ with rigid ions described by modified constant point charges $q_{\mathrm{Si}}=1.2 e$ and $q_{\mathrm{O}}=-0.6 e$, and atoms assumed to bind to each other via polar covalent bonds. These charges have been fitted to reproduce the electrostatic field in the pores of the zeolitic framework materials described using PBCs. When we define a QM cluster embedded in a siliceous system, we have to cut through $\mathrm{Si}-\mathrm{O}$ bonds that connect atoms, one in the QM and the other in the MM regions. As under-coordinated QM atoms on the QM region boundary are terminated with hydrogens, an artificial strain on the system is introduced due to spurious interactions between the hydrogen and the nearest neighbours in the MM region. To remedy this artefact, a charge on the corresponding MM atoms is shifted outwards, further onto the next nearest neighbours, whereas the dipole created by such a shift is compensated locally by a pair of point charges placed along the corresponding bonds. Further information on the method can be found in the original publications, and relevant model construction details are given below.

Next, we provide a short outline of our earlier work on metal centres in zeolites, which illustrate the power of our approach and its potential in the elucidation of the structure and properties of catalytically active sites in zeolites.

\section{Applications to metal centre in zeolites}

Incorporation of metal sites in zeolitic frameworks has been the subject of numerous investigations. In particular, Ti doped silicalite-1 (TS-1), ${ }^{21}$ a siliceous counterpart of ZSM-5, has been of great interest, since it is used with aqueous $\mathrm{H}_{2} \mathrm{O}_{2}$ as the primary oxidant in a large number of important reactions such as the epoxidation of linear olefins, oxidation of linear alkenes to alcohols and ketones, 


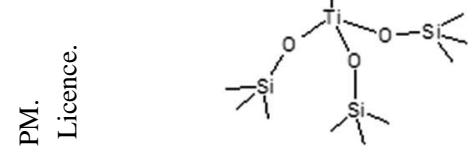

(a)

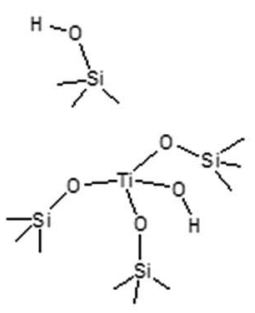

(d)

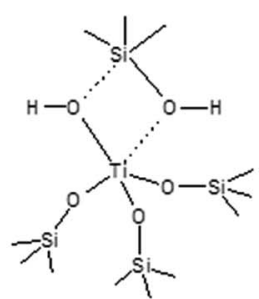

(b)

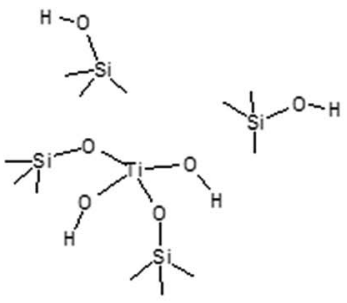

(e)

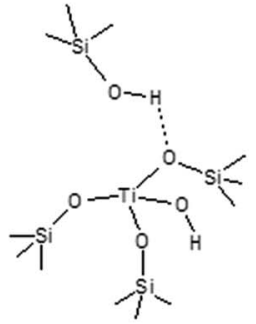

(c)

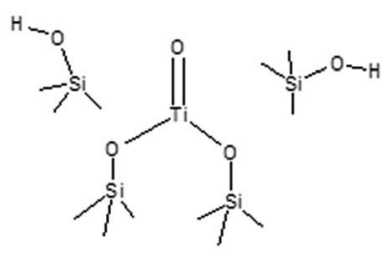

(f)

Fig. 2 The six models used to represent the active Ti sites in TS-1: (a) tetrapodal, (b) 2MR, (c) tripodal (1l), (d) tripodal (2l), (e) bipodal, and (f) titanyl.

oxidation of alcohols, hydroxylation of aromatics, oxidation of amines, and oxidation of sulphur compounds and ethers. ${ }^{22}$

In our work, ${ }^{23-25}$ we have proposed a number of structural models for a $\mathrm{Ti}$ species that would result from the framework hydrolysis and site inversion that can take place during the synthesis and post-synthetic treatment and/or, depending on the catalytic process, occur as a part of the catalytic transformation. The models of interest are shown in Fig. 2.

The geometrical parameters of the tripodal sites obtained with ChemShell calculations proved to be in excellent agreement with experimental EXAFS data, ${ }^{26}$ and therefore could be usefully employed to rationalise the difference in the observed spectroscopic signature of metal centres in differently treated samples, as summarised in Table 1.

Our analysis of site transformation in the presence of water, illustrated in Fig. $3{ }^{27}$ allowed us to draw the crucial conclusion that the catalytically active sites in TS- 1 are hydrated tripodal rather than tetrapodal, which is strikingly similar to Ti doped mesoporous materials that had been previously explored using simple cluster models. ${ }^{28}$

Further, we consider the site reactivity towards $\mathrm{H}_{2} \mathrm{O}_{2}$ in anhydrous and hydrous conditions according to the reaction pathways drawn in Fig. 4 and $5 .^{29}$

Our calculations confirmed the close competition between the $\eta^{1}$ and $\eta^{2}$ complexes as candidates for the oxygen donating species in TS-1. Curiously, a much higher energy (by ca. 400-450 $\mathrm{kJ} \mathrm{mol}^{-1}$ ) superoxide radical species has also been reported (from EPR studies) to emerge as a result of interaction of aqueous $\mathrm{H}_{2} \mathrm{O}_{2}$ and non-aqueous urea $\mathrm{H}_{2} \mathrm{O}_{2} \cdot{ }^{30}$ Our calculations unambiguously identified the superoxide supported on tripodal $\mathrm{Ti}$ as the magnetically active 
Table 1 Comparison of selected structural parameters of (a) the tripodal (1l) and (b) tripodal (2I) Ti models

(a)

\begin{tabular}{|c|c|c|c|c|c|c|}
\hline & \multicolumn{2}{|c|}{ Ti-O distance $[\AA]$} & \multicolumn{2}{|c|}{ Ti-Si distance $[\AA]$} & \multicolumn{2}{|c|}{ Ti-O-Si angle $\left[^{\circ}\right]$} \\
\hline & $\begin{array}{l}\text { Tripodal } \\
\text { (1I) }\end{array}$ & $\begin{array}{l}\text { Expt. }^{a} \\
\text { untreated }\end{array}$ & Tripodal (1I) & $\begin{array}{l}\text { Expt. }^{a} \\
\text { untreated }\end{array}$ & Tripodal (1I) & $\begin{array}{l}\text { Expt. }^{a} \\
\text { untreated }\end{array}$ \\
\hline \multirow[t]{4}{*}{$\mathrm{Ti}$} & 1.76 & $1.81 \pm 0.02$ & 3.16 & $3.18 \pm 0.02$ & 133 & $140 \pm 5$ \\
\hline & 1.79 & & 3.27 & $3.30 \pm 0.02$ & 153 & $152 \pm 5$ \\
\hline & 1.83 & & 3.37 & $3.39 \pm 0.02$ & 164 & $167 \pm 5$ \\
\hline & $1.75^{b}$ & & & & & \\
\hline
\end{tabular}

(b)

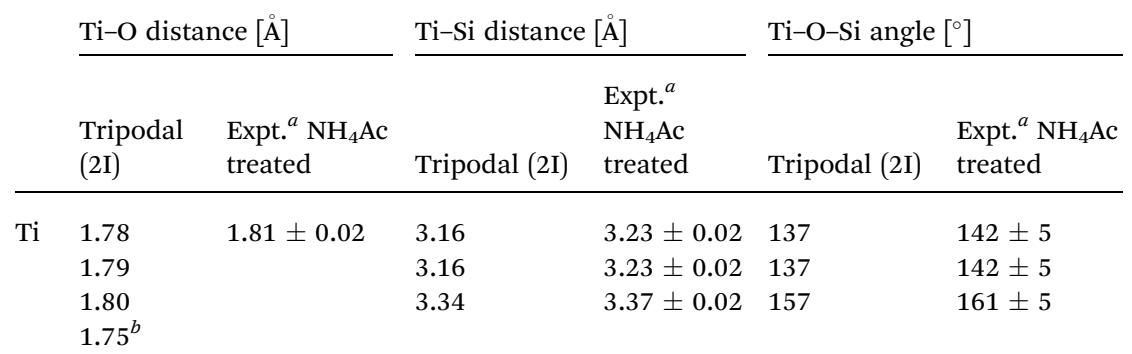

${ }^{a}$ Ref. 26. ${ }^{b}$ Refers to the Ti-OH bond.

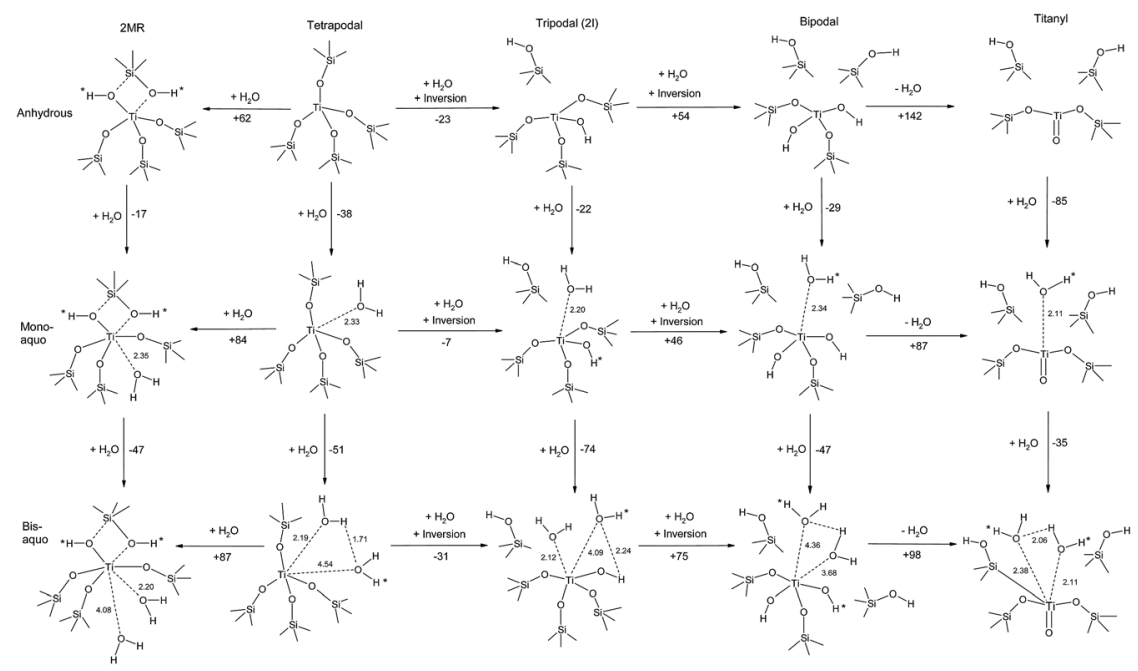

Fig. 3 Calculated energy differences in $\mathrm{kJ} \mathrm{mol}^{-1}$ of five models chosen as representatives of Ti sites in TS-1, with and without one and two molecules of water. The dashed lines highlight the bonding between $\mathrm{Ti}$ and the oxygen atoms in water and the hydrogen bonding within the framework. ${ }^{*} \mathrm{H}$ indicate atoms that are hydrogen bonding with framework oxygen atoms. 
(a)

(b)
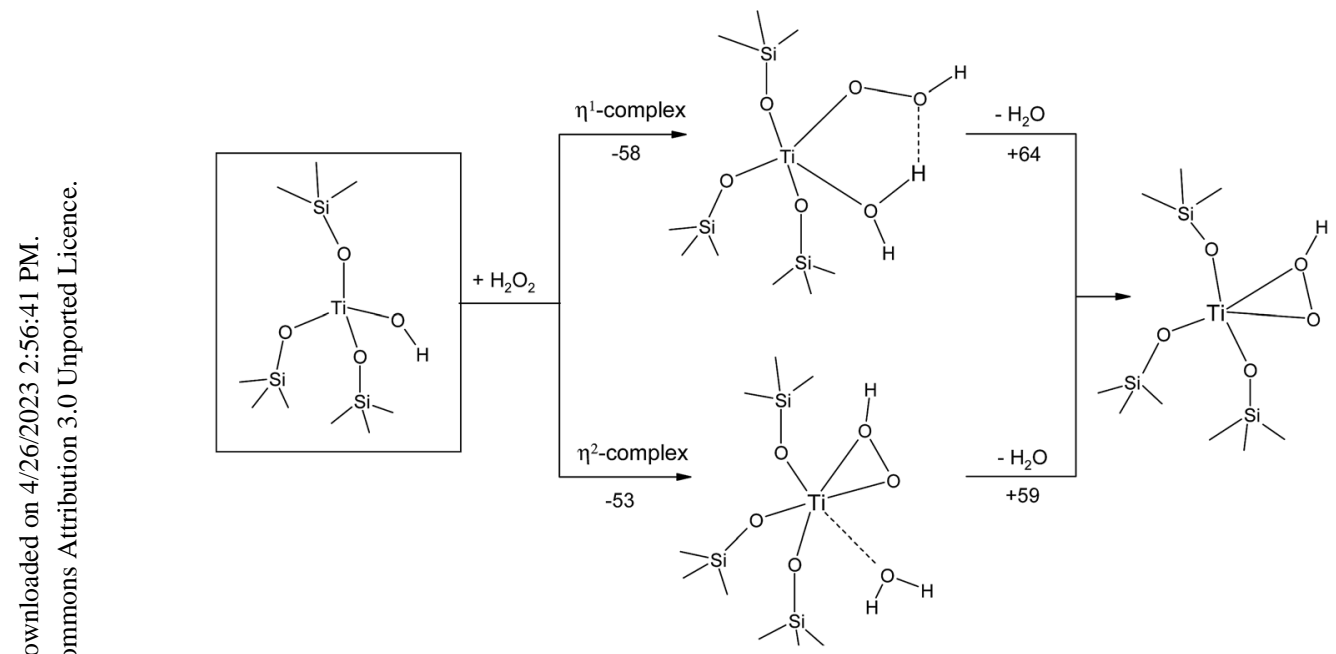

Fig. 4 Reaction pathways for the $\mathrm{Ti}-\eta^{1}(\mathrm{OOH})$ and $\mathrm{Ti}-\eta^{2}(\mathrm{OOH})$ formation (a) with and (b) without one water. Energies in $\mathrm{kJ} \mathrm{mol}^{-1}$.
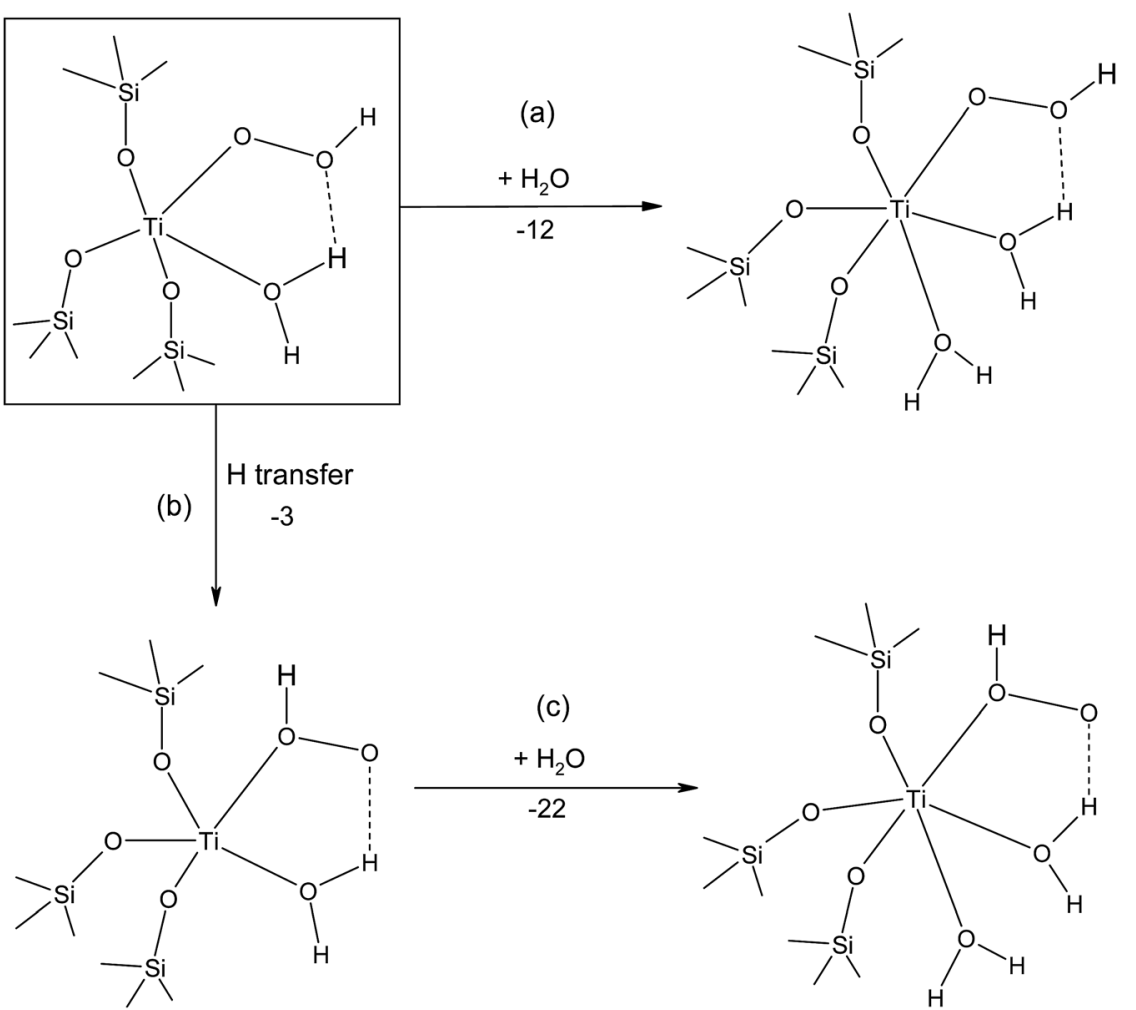

(c)

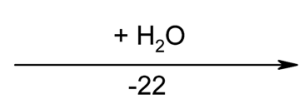

Fig. 5 Reaction pathways for the formation of (a) six-coordinated $\mathrm{Ti}-\eta^{1}(\mathrm{OOH})$, (b) fivecoordinated $\mathrm{Ti}-\eta^{1}(\mathrm{OOH})$ and (c) six-coordinated $\mathrm{Ti}-\eta^{1}(\mathrm{O}(\mathrm{H}) \mathrm{OH})$ species. Energies in $\mathrm{kJ} \mathrm{mol}^{-1}$. 
Table 2 EPR spin Hamiltonian parameters of the $\mathrm{Ti}\left(\mathrm{OO}^{*}\right)$ radical species

\begin{tabular}{llll}
\hline & & Experiment ${ }^{a}$ & \\
\cline { 3 - 4 }$g$ tensor & at BB1K geometry & Aqueous $\mathrm{H}_{2} \mathrm{O}_{2}$ & Urea- $\mathrm{H}_{2} \mathrm{O}_{2}$ \\
\hline$g_{x}$ & 2.003 & 2.002 & 2.004 \\
$g_{y}$ & 2.010 & 2.009 & 2.010 \\
$g_{z}$ & 2.025 & 2.026 & 2.028 \\
${ }^{a}$ Ref. 30. & & & \\
& & &
\end{tabular}

centre with the spectroscopic signature in close agreement with the experiment as shown in Table 2.

From this short outline, we conclude that the hybrid QM/MM methodology implemented in ChemShell provides us with a reliable tool to investigate both the structure and physical and chemical properties of active sites in zeolites. In the next section we employ ChemShell in a study of methoxylation of two zeolites with very different behaviour.

\section{Methanol-active site interactions in zeolites}

The zeolite catalysed conversion of methanol to hydrocarbons (MTH) has been researched significantly since its initial discovery by Chang and Silvestri, ${ }^{31}$ with the first commercialization of the MTH process in New Zealand in $1985 .^{32}$ Demand for light olefins has also lead to extensive research into the use of zeolitic catalysts for converting methanol to olefins (MTO). ${ }^{33}$

An early step of interest in the reaction mechanism is the formation of framework methoxy species after initial physisorption of methanol through $\mathrm{H}$ bonding to the zeolite Brønsted acid site. ${ }^{34-36}$ However, studying such species experimentally is difficult, as secondary reactions dominate rapidly at higher temperatures. ${ }^{37}$ Recent studies using neutron scattering ${ }^{38}$ have observed the total conversion of methanol to framework methoxy at room temperature in commercial samples of H-ZSM-5 (in contrast to previous experiments discussed in ref. 38, which suggest that elevated temperatures are necessary), which is, however, not observed in commercial samples of $\mathrm{H}-\mathrm{Y}$ with the same $\mathrm{Si} / \mathrm{Al}$ ratio. This difference was attributed to the necessary dealumination procedure for high silica H-Y synthesis (creating defects which decrease the activity). However, detailed theoretical studies into the effect of framework topology on methanol behaviour in zeolite catalysts are necessary for improved understanding and further catalyst design. A short discussion of theoretical studies of methanol behaviour in zeolite catalysts will now follow.

Though the MTG/MTO process has received a significant amount of attention from a theoretical perspective, ${ }^{39,40}$ the aforementioned earlier steps are not understood in detail. $A b$ initio studies of methanol adsorption began with small aluminosilicalite clusters. ${ }^{\mathbf{4 1 , 4 2}}$ Numerous studies using three tetrahedral site clusters have concluded that the hydrogen bonding of the methanol oxygen with the Brønsted acid hydroxyl is exothermic, generally calculating adsorption energies of between 50 and $100 \mathrm{~kJ} \mathrm{~mol}^{-1} \cdot \cdot^{35,36,43-45}$ It has also been found that there is an 
energetic difference between 'side-on' and 'end-on' adsorption, with the end-on geometry (where the methyl group protrudes almost perpendicularly from the aluminosilicate cluster) calculated to be more favourable, and methoxylation taking place via the rapid equilibration between the end-on and side-on geometry. ${ }^{43,46}$ All studies into the methoxylation process using clusters conclude a barrier to methoxylation with values of $\sim 180-225 \mathrm{~kJ} \mathrm{~mol}^{-1} .^{35,36,43,45,46}$ Methoxylation and adsorption has also been studied in periodic zeolite structures, with static calculations showing endothermic methoxylation in chabazite (with a barrier of $\left.56 \mathrm{~kJ} \mathrm{~mol}^{-1}\right),{ }^{47}$ and DFT-MD giving an adsorption energy of $-94 \mathrm{~kJ}$ $\mathrm{mol}^{-1} \cdot{ }^{48}$ Andzelm and Govind ${ }^{49}$ studied the methoxylation process in a periodic ferrierite structure, finding a methoxylation barrier of $226 \mathrm{~kJ} \mathrm{~mol}^{-1}$. However, it was found that when a second methanol molecule was added to the system, the barrier to methoxylation was then reduced by $42 \mathrm{~kJ} \mathrm{~mol}^{-1}$ due to the formation of hydrogen bonding networks spanning the width of the channel, which significantly stabilise the methoxylation transition states.

We note that the use of a discrete cluster model is less accurate than the use of a periodic zeolite structure, due to the lack of any long-range electrostatic potential influencing the system energetics. However, as noted earlier, in addition to being computationally expensive in calculations involving large unit cells, the use of periodic boundary conditions can bring problems when calculating reaction barriers and adsorption energetics, such as incomplete relaxation of the system or the influence of the interaction between sorbate mirror images. This problem can be especially significant when comparing the effect of the framework structure on sorbate behaviour. A large zeolite unit cell would minimise the effect of these sorbate-sorbate interactions on the methoxylation process compared to, say, chabazite where they may become significant. These complications can be bypassed using the quantum mechanical/molecular mechanical (QM/MM) embedded cluster technique ${ }^{9,50}$ outlined in the previous section, where large framework structures may be modelled relatively cheaply, providing an accurate electrostatic potential that will affect the behaviour and reactivity at an active site.

We present a comparison of the deprotonation, methanol adsorption, and methoxylation energies in H-ZSM-5 and H-Y zeolite frameworks, in an attempt to investigate the effect of framework topology and active site location on reactive sorbate behaviour. The deprotonation energy is first investigated as it is a major factor controlling the Brønsted acidity of the differing frameworks; our calculations include a comparison of three different sites in the ZSM-5 structure. The adsorption energy of methanol at these sites is then compared to quantify the differences in interaction strength between methanol and the differing acidic hydroxyl sites, after which the methoxylation energy is then calculated to quantify the effect of these differing environments on the reaction.

\section{Methodology}

We first discuss the construction of the embedded cluster models for the $\mathrm{H}-\mathrm{Y}$ and H-ZSM-5. We begin with the purely siliceous spherical structure generated from the periodic experimental unit cell structure of silicalite ${ }^{51}$ and siliceous faujasite. ${ }^{52}$ The use of the experimental unit cell is assumed to have minimal effects on the geometric and electronic structure. Each spherical cluster centres on a Si T-site. 
a

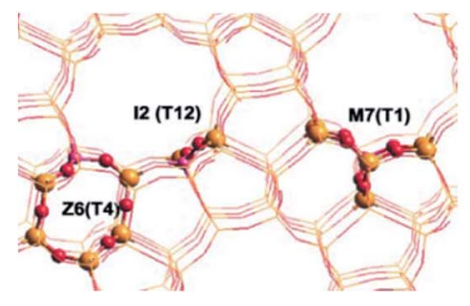

c)

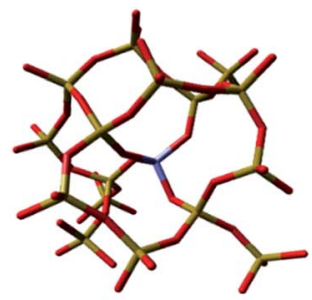

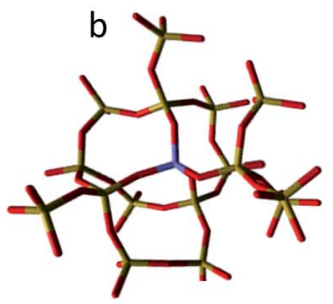

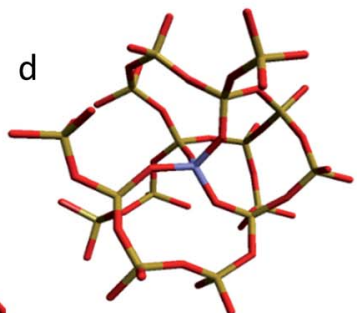

Fig. 6 (a) The locations of the I2, Z6 and M7 clusters in the MFI framework (reproduced from ref. 54 with permission from the PCCP Owner Societies), and the optimised QM clusters for the (b) 12, (c) M7, (d) Z6 sections of the MFI framework, along with the optimised QM cluster in the zeolite Y calculations (e). The central T-site is coloured purple.

Only one cluster is generated for the $\mathrm{H}-\mathrm{Y}$ structure as the tetrahedral sites are equivalent, which, however, is not the case for H-ZSM-5. Therefore, three embedded clusters are generated based on three sites in the ZSM-5 structure: ${ }^{53}$ a T-site at the straight channel (M7-T1), the sinusoidal channel (Z6-T4) and the channel intersections (I2-T12). The clusters, including their locations in the MFI structure are shown in Fig. 6. ${ }^{54}$

The QM region is expanded from the central atom to include the fifth neighbour, i.e. the third oxygen atom away from the T-site as shown in Fig. 6. The cluster is then terminated with hydrogen atoms. We also include two
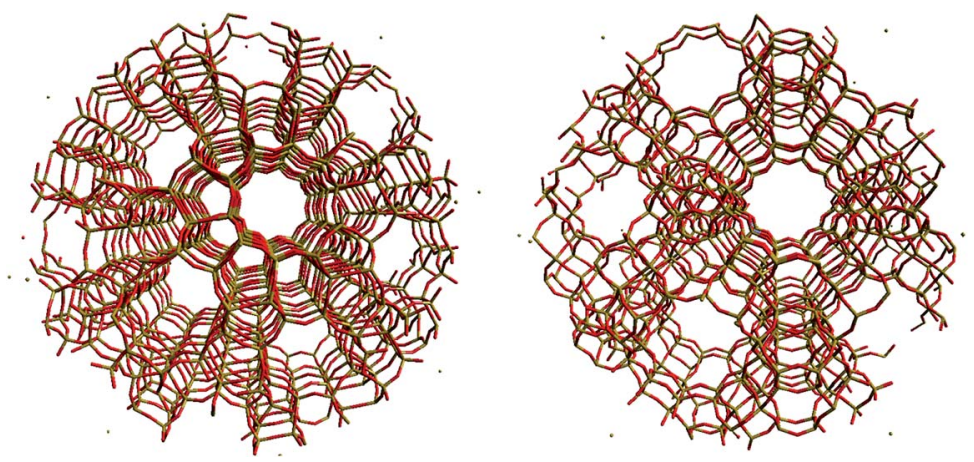

Fig. 7 Spherical embedded cluster models of the 12-T12 centred H-ZSM-5 system (left) and the zeolite $Y$ system (right). 
concentric regions of molecular mechanics (MM) atoms spherically around this QM cluster (Fig. 7). The MM atoms in the first concentric region are allowed to relax during the energy calculation; this region reaches a radius of $10.58 \AA$ (20 bohr) from the central atom. Beyond this region, the framework atoms in the next concentric region are fixed, reaching a radius of $21.17 \AA$ (40 bohr) from the central T-site. The total number of atoms in each cluster was 1653 for H-Y, 2165 for H-ZSM-5 (I2), 2180 for H-ZSM-5 (M7) and 2155 for H-ZSM-5 (Z6). Due to the termination of the incomplete bonds in the QM cluster by hydrogen atoms upon embedding into the MM region, a bond-dipole correction must, as noted above, be added to the boundaries of the MM region. ${ }^{5}$

The MM interactions are represented using the forcefield of Hill and Sauer, ${ }^{19,20}$ and the QM atoms are treated using the Ahlrichs and Taylor TZVP Gaussian basis sets. ${ }^{55}$ Three exchange-correlation functionals are used in our calculations: the GGA functional of Perdew and Wang (PW91), ${ }^{56}$ and the first and second generation hybrid functionals of Becke, Lee, Yang and Parr (B3LYP) ${ }^{57-60}$ and Wilson, Bradley and Tozer (B97-2) trained by the reproduction of accurate thermodynamic properties of atoms and small molecules. ${ }^{61}$

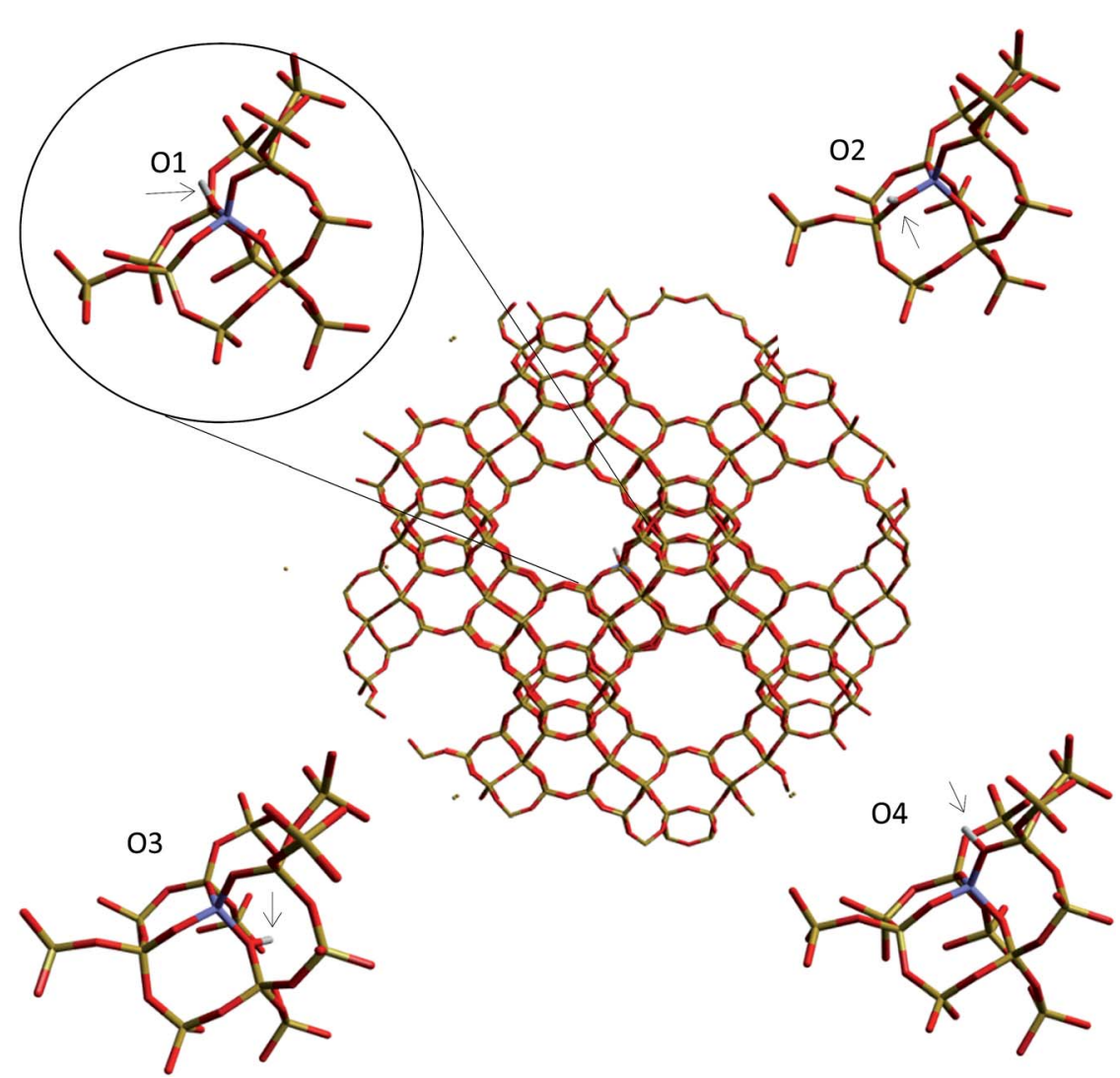

Fig. 8 Oxygen sites from which the deprotonation energy is calculated around the aluminium substitution in the $\mathrm{H}-\mathrm{Y}$ cluster. 
The calculation of the energy and gradients of the QM region used the GamessUK package, ${ }^{62}$ and the calculation of the energy and gradients of the MM region employed the DL_POLY package ${ }^{63}$ with the QM and MM calculations coupled in the ChemShell environment. ${ }^{53}$ Electronic minimisation was deemed complete for the QM system when the energy variation was below a threshold of $2.72 \times 10^{-6} \mathrm{eV}$ was achieved $\left(1 \times 10^{-7} \mathrm{Ha}\right)$. The geometries were optimised using the LimitedMemory Broyden-Fletcher-Goldfarb-Shanno (L-BFGS $)^{64-67}$ algorithm with a convergence threshold of $0.015 \mathrm{eV}^{-1}$.

\section{Results and discussion}

2.1. Calculation of deprotonation energies. In our first comparison of $\mathrm{H}-\mathrm{Y}$ and H-ZSM-5, we investigate the deprotonation energy differences between the structures. The deprotonation energy influences acidity ${ }^{68-70}$ as a lower deprotonation energy will favour protonation of any sorbate. We begin by determining the oxygen site around the central aluminium T-site, that has the lowest deprotonation energy. This site will then be used for further studies into the methanol adsorption, and the later methoxylation studies. We define the deprotonation energy as:

$$
E_{\mathrm{dp}}=E_{\mathrm{zeoH}}-E_{\mathrm{zeo}}{ }^{-} .
$$

Here, $E_{\mathrm{zeoH}}$ is the energy of the protonated zeolite and $E_{\mathrm{zeo}}{ }^{-}$is the energy of the deprotonated zeolite. Polarisation effects outside of our active region, where all

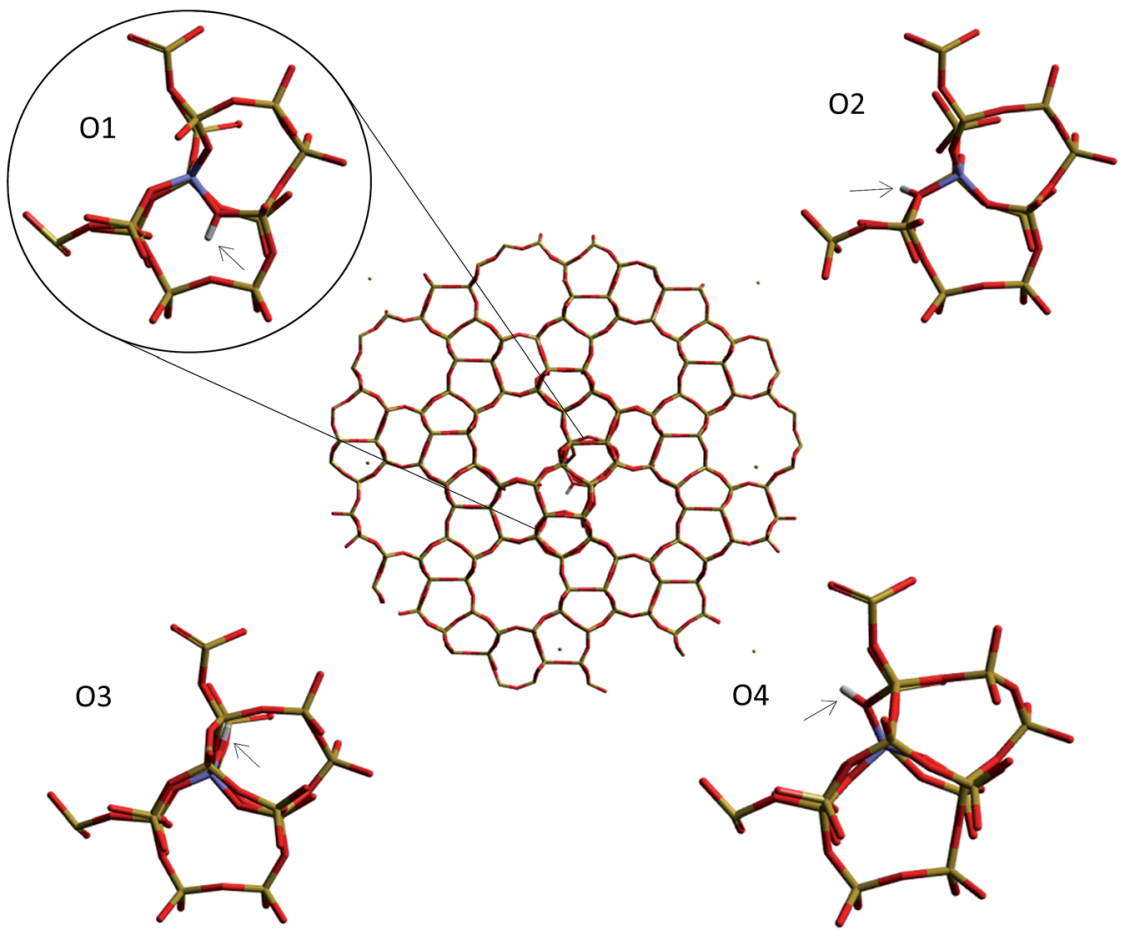

Fig. 9 Oxygen sites around the aluminium substitution in the H-ZSM-5 (I2-T12) cluster for which the deprotonation energy is calculated. 


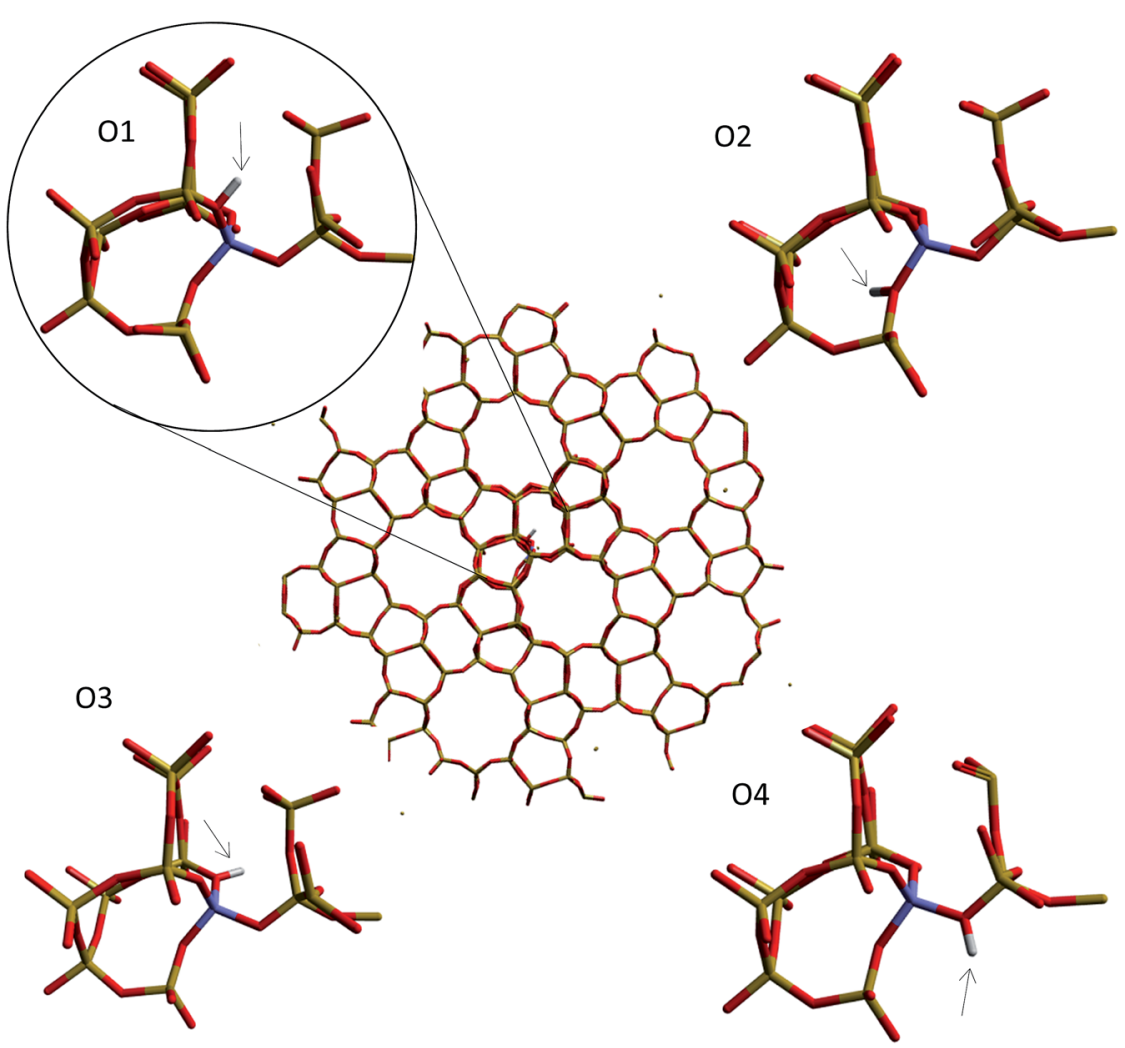

Fig. 10 Oxygen sites around the aluminium substitution in the H-ZSM-5 (M7-T1) cluster for which the deprotonation energy is calculated.

atoms relax during geometry optimisation, are neglected in the following discussion as they represent a relatively constant shift in the deprotonation energies for all Brønsted sites considered $\left(<50 \mathrm{~kJ} \mathrm{~mol}^{-1}\right.$ using Born and Jost's formulae ${ }^{9,71}$ ). Fig. 8-11 show geometries of the four protonated systems around the central $\mathrm{Al} \mathrm{T-site} \mathrm{in} \mathrm{each} \mathrm{zeolite} \mathrm{system,} \mathrm{labelled} \mathrm{O1-O4.} \mathrm{The} \mathrm{deprotonation}$ energies of each oxygen site were calculated using the PW91 exchange correlation functional and are listed in Table 3.

Using the PW91 functional, the most acidic oxygen sites are $\mathrm{O} 1 \mathrm{Hor} \mathrm{H}-\mathrm{Y}, \mathrm{O} 3$ for H-ZSM-5 (I2), O3 for H-ZSM-5 (M7) and O2 for H-ZSM-5 (Z6). The difference between the lowest and highest deprotonation energies, which are respectively $\mathrm{H}$ $\mathrm{Y}$ and H-ZSM-5 (M6), is $90.2 \mathrm{~kJ} \mathrm{~mol}^{-1}$. H-Y has the lowest deprotonation energy of the series, followed by ZSM-5 (Z6) located in the sinusoidal channel, ZSM-5 (I2) in the intersections, and the T-site with the highest deprotonation energy is in the straight channel (M7).

We now study the deprotonation energies of the most acidic sites in each structure using the B3LYP and B97-2 hybrid exchange-correlation functionals, as listed in Table 4. The deprotonation energies calculated using the B3LYP functional were higher than when using the PW91 functional, and higher still using the B97-2 functional, which can be attributed to the superior representation of the 


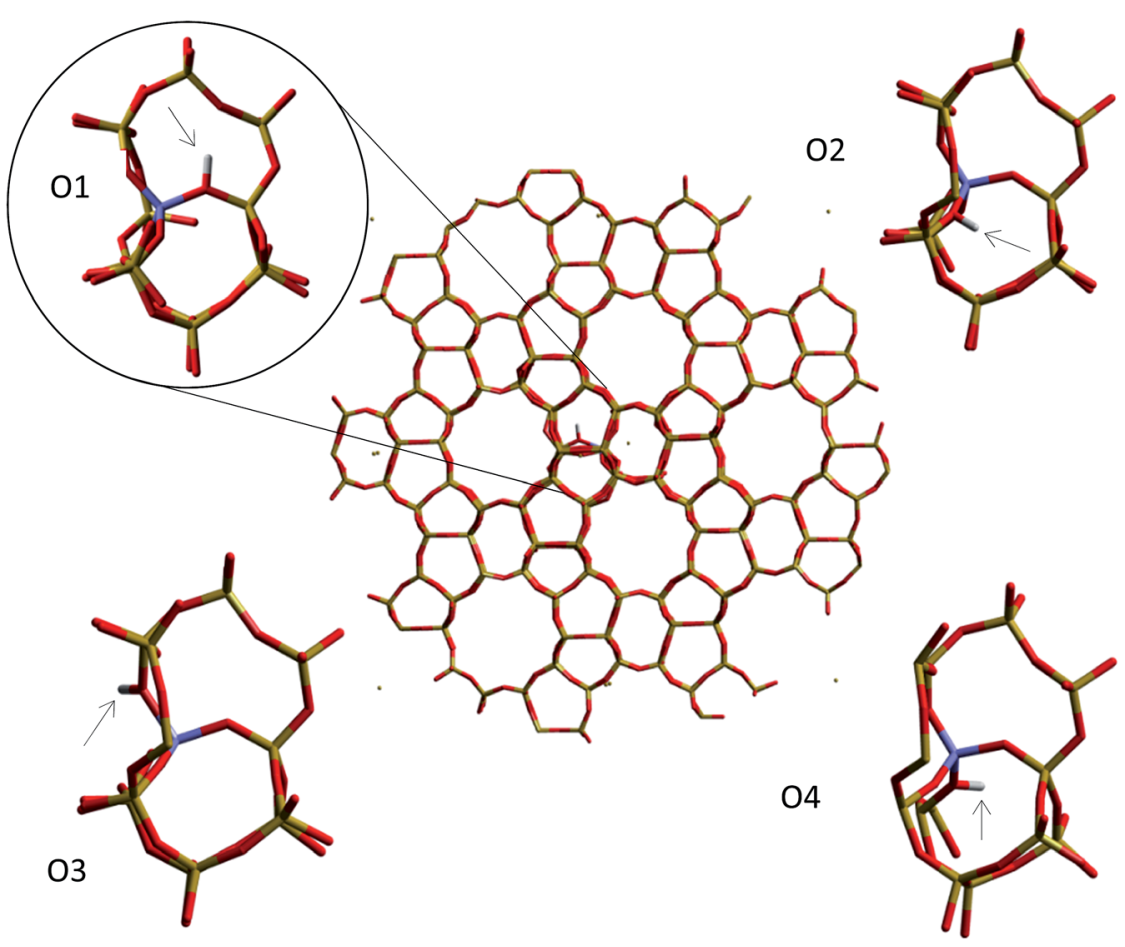

Fig. 11 Oxygen sites around the aluminium substitution in the H-ZSM-5 (Z6-T4) cluster for which the deprotonation energy is calculated.

Table 3 Calculated deprotonation energies of each zeolite structure, with the most acidic oxygen atoms highlighted in bold

\begin{tabular}{lllll}
\hline & \multicolumn{2}{l}{$E_{\mathrm{dp}} \mathrm{kJ} \mathrm{mol}^{-1}$} \\
\cline { 2 - 5 } Cluster & $\mathrm{O} 1$ & $\mathrm{O} 2$ & $\mathrm{O} 3$ & $\mathrm{O} 4$ \\
\hline HY & $\mathbf{1 0 1 3 . 4}$ & 1041.0 & 1031.8 & 1023.0 \\
H-ZSM-5 (I2) & 1099.2 & 1106.3 & $\mathbf{1 0 9 3 . 4}$ & 1122.0 \\
H-ZSM-5 (M7) & 1123.6 & 1114.7 & $\mathbf{1 1 0 3 . 6}$ & 1109.5 \\
H-ZSM-5 (Z6) & 1059.5 & $\mathbf{1 0 2 0 . 9}$ & 1042.9 & 1061.0
\end{tabular}

localised electrons in the zeolite due to the exact exchange interaction from Hartree-Fock methods incorporated into the hybrid functionals. However, the ranking of the deprotonation energy is maintained as H-Y $<\mathrm{H}-\mathrm{ZSM}-5$ (Z6) $<\mathrm{H}-$ ZSM-5 (I2) < H-ZSM-5 (M7) for all functionals. The deprotonation energy of 1093.4 $\mathrm{kJ} \mathrm{mol}^{-1}$ calculated for ZSM-5 (I2) is $122 \mathrm{~kJ} \mathrm{~mol}^{-1}$ lower than obtained by ab initio molecular dynamics for the MFI structure ${ }^{70}$ using the same PW91 functional. Possible reasons for this difference could be the aforementioned sorbate-sorbate interactions, the more complete representation of polarisation afforded using the QM/MM method, or the charge compensation parameters needed for periodic DFT calculations. We also note that ref. 70 used a different intersectional T-site 
Table 4 Calculated deprotonation energies of each zeolite structure, with three different functionals, in $\mathrm{kJ} \mathrm{mol}^{-1}$

$E_{\mathrm{dp}}$

\begin{tabular}{lccc} 
Cluster & PW91 & B3LYP & B97-2 \\
\hline HY & 1013.4 & 1065.9 & 1081.3 \\
H-ZSM-5 (I2) & 1093.4 & 1100.4 & 1114.1 \\
H-ZSM-5 (M7) & 1103.6 & 1155.9 & 1166.1 \\
H-ZSM-5 (Z6) & 1020.9 & 1084.7 & 1101.9
\end{tabular}

(T7) from ours (T12). On the whole our results correlate well with the data from the other computational studies in the literature. ${ }^{16,72,73}$

2.2. Calculation of methanol adsorption energies. The interaction of methanol with the active site is investigated by calculating the adsorption energies of methanol in H-Y and H-ZSM-5. Though the acidity of a zeolite is a typical indicator of the activity in a catalytic process, the magnitude of the sorbate interaction with the active site may also be a deciding factor in a methoxylation process. We note that although a favourable adsorption energy can facilitate the process, it may also hinder the methoxylation through increasing the barrier to the reaction. The adsorption energy of methanol is calculated as:

$$
E_{\mathrm{ads}}=\left(E_{\mathrm{MeOH}+\mathrm{ZeoH}}-E_{\mathrm{BSSE}}\right)-\left(E_{\mathrm{MeOH}}+E_{\mathrm{ZeoH}}\right),
$$

where $E_{\mathrm{MeOH}}$ is the calculated energy of a methanol molecule in vacuo, $E_{\mathrm{ZeoH}}$ is the energy of the protonated embedded zeolite cluster, $E_{\mathrm{MeOH}+\mathrm{ZeoH}}$ is the energy of the methanol adsorbed onto the protonated embedded zeolite cluster, and $E_{\mathrm{BSSE}}$ is the basis set superposition error calculated using the counterpoise correction method. ${ }^{74}$ The geometry of the adsorbed methanol for each cluster, after optimisation with the B3LYP functional, is shown in Fig. 12.

We have studied the 'side-on' adsorption in all zeolite systems. Though we note in previous studies that 'end-on' adsorption is preferred, ${ }^{43,46}$ the side-on adsorption is more conducive to methoxylation, as is the emphasis of this study, and the barriers to this switching between the geometries are very small and may be overcome under experimental conditions. From Fig. 12 it is observed that the $\mathrm{H}$-bond length between the hydroxyl site and the methanol hydroxyl is $1.476 \AA$ for the $\mathrm{H}-\mathrm{Y}$ cluster and 1.452-1.478 $\AA$ for the H-ZSM-5 clusters, with the shortest $\mathrm{H}$ bond being in the M7-T1 cluster despite having the highest deprotonation energy. However, we note that the range of bond distances of $0.026 \AA$ is quite small and so a correlation with deprotonation energies is not necessarily meaningful.

We should note that the BSSE values were calculated with the B3LYP functional only. As an approximation, we have then taken the percentage error (5.5\%) that these values contribute to each system and applied it to the adsorption energy calculations using the PW91 and B97-2 functionals. The calculated adsorption energies are listed in Table 5 after subtraction of this percentage error.

For all functionals, the order of methanol adsorption energy is H-ZSM-5 (M7) < H-Y $<$ H-ZSM-5 (I2) < H-ZSM-5 (Z6). We note that the difference in adsorption between the most favourable site, H-ZSM-5 (M7), and the least favourable site, $\mathrm{H}^{-}$ ZSM-5 (Z6), is between 60 and $70 \mathrm{~kJ} \mathrm{~mol}^{-1}$, depending on the functional used. The 
a)

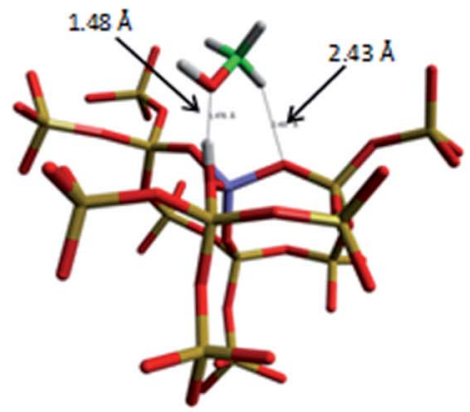

c)

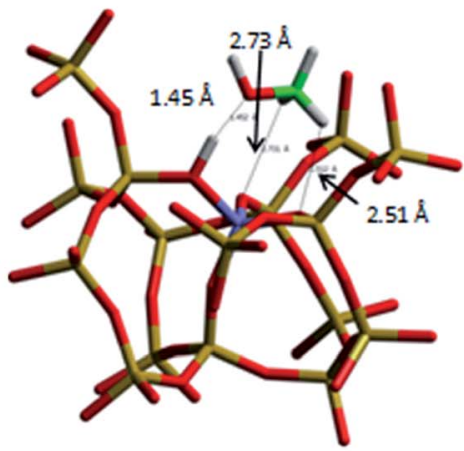

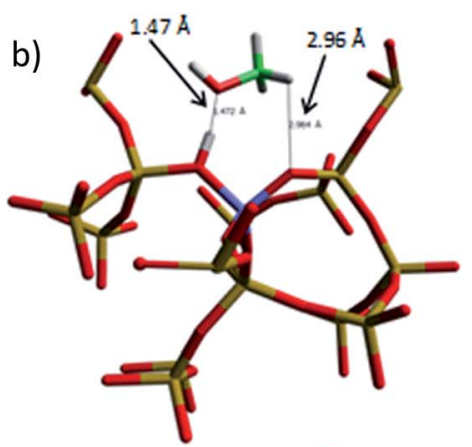

d)

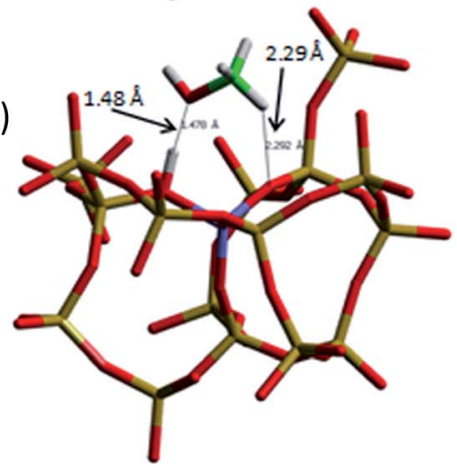

Fig. 12 Optimised adsorbed geometry of methanol in (a) $\mathrm{H}-\mathrm{Y}$, (b) $\mathrm{H}-\mathrm{ZSM}-5$ (I2), (c) $\mathrm{H}-$ ZSM-5 (M7), and (d) H-ZSM-5 (Z6).

methanol in the H-ZSM-5 (M7) system is H-bonded to two framework oxygens by two $\mathrm{C}-\mathrm{H}$ hydrogens (depicted in Fig. 12c), suggesting that this geometry is more favourable than a short, single $\mathrm{C}-\mathrm{H} \cdots \mathrm{O}$ bond, as is demonstrated by the less favourable adsorption energy in the H-ZSM-5 (Z6) system. It may be significant that the most favourable adsorption process also occurs at the site with the highest deprotonation energy, but we also see that the site with the lowest deprotonation energy ( $\mathrm{H}-\mathrm{Y})$ has the second lowest adsorption energy. The calculated adsorption energy for methanol in ZSM-5 (M7) appears anomalous when considering the overall correlation between deprotonation and methanol adsorption energies for FAU and MFI, however it is perhaps more reasonable to consider that there should not be a correlation at all, and in fact the adsorption

Table 5 Corrected adsorption energies of methanol $\left(E_{\text {ads }}\right)$, in $\mathrm{kJ} \mathrm{mol}^{-1}$, using three different functionals

\begin{tabular}{llcr}
\hline Cluster & PW91 & B3LYP & B97-2 \\
\hline HY & -180.2 & -179.6 & -180.4 \\
H-ZSM-5 (I2) & -186.8 & -177.5 & -168.9 \\
H-ZSM-5 (M7) & -215.1 & -194.8 & -206.9 \\
H-ZSM-5 (Z6) & -147.24 & -136.6 & -136.7
\end{tabular}


energy is dominated by the H-bonding capability of the methyl group of the methanol. We note that previous calculations of Svelle et al. reported a weaker adsorption for methanol at the I2-T12 site than we present here: $\mathrm{E}_{\mathrm{ads}}$ was calculated as -86 and $-114 \mathrm{kJmol}^{-1}$ when using a periodic model with the PBE and PBE-D exchange-correlation functionals, respectively. ${ }^{75}$ Preliminary comparative calculations indicate that the electrostatic embedding environment makes a stronger contribution to our adsorption energy, but the significant contrast between our model and that of Svelle et al. necessitates further investigation before any certain conclusions can be drawn.

2.3. Calculation of methoxylation energies. We calculated the energy of methoxylation for each cluster. The energy is defined as:

$$
E_{\text {methox }}=E_{\text {ZeoMe(aq) }}-\left(E_{\mathrm{MeOH}}+E_{\mathrm{ZeoH}}\right),
$$

where $E_{\text {ZeoMe(aq) }}$ is the calculated energy of the methoxylated species with the neighbouring product water molecule. The energy change associated with this process should act as a marker for reactivity differences between the two frameworks and the differing sites within the MFI framework. The methoxylation geometries were based on those obtained by Andzelm and Govind ${ }^{49}$ from the $\mathrm{S}_{\mathrm{N}} 2$ mechanism followed from the original side-on adsorption geometry, where the resultant water molecule $\mathrm{H}$-bonds to the formerly protonated oxygen, and the methyl group is attached to the adjacent oxygen across from the aluminium Tsite. The geometries were optimised and energies calculated using solely the B3LYP functional. The values of $E_{\text {methox }}$ are listed in Table 6, along with the difference between $E_{\text {ads }}$ and $E_{\text {methox }}$. The optimised methoxylation geometries are shown in Fig. 13.

Firstly, we note that all the methoxylation energies are exothermic overall but are endothermic with regard to the adsorbed methanol molecule, as observed in previous cluster simulations ${ }^{35}$ and in the periodic chabazite structure. ${ }^{42} \mathrm{We}$ observe that the order of the methoxylation energy is $\mathrm{H}-\mathrm{Y}<\mathrm{H}-\mathrm{ZSM}-5$ (I2) $<\mathrm{H}-\mathrm{ZSM}-$ 5 (M7) < H-ZSM5-I2 (Z6), in agreement with deprotonation energies but in contrast to the order of methanol adsorption energies shown in the previous section. This suggests that the tendency of methoxylation is not related directly to the adsorption energy, at least when only one methanol molecule is present in the immediate environment.

Finally, we turn our attention to the geometries of the methoxylated system. The most exothermic methoxylation takes place in $\mathrm{H}-\mathrm{Y}$, which is also the more coordinated system: the water molecule is coordinated to three framework oxygen

Table 6 Methoxylation energies (in $\mathrm{kJ} \mathrm{mol}^{-1}$ ) of the four zeolite systems and the energy difference between the adsorbed state and the methoxylated state

\begin{tabular}{lcc}
\hline System & $E_{\text {methox }}$ & $E_{\text {ads }}-E_{\text {methox }}$ \\
\hline Me-Y $+\mathrm{H}_{2} \mathrm{O}$ & -162.0 & +17.6 \\
Me-ZSM-5 (I2) $+\mathrm{H}_{2} \mathrm{O}$ & -150.4 & +27.1 \\
Me-ZSM-5 (M7) $+\mathrm{H}_{2} \mathrm{O}$ & -138.6 & +56.2 \\
Me-ZSM-5 (Z6) $+\mathrm{H}_{2} \mathrm{O}$ & -118.0 & +18.6
\end{tabular}



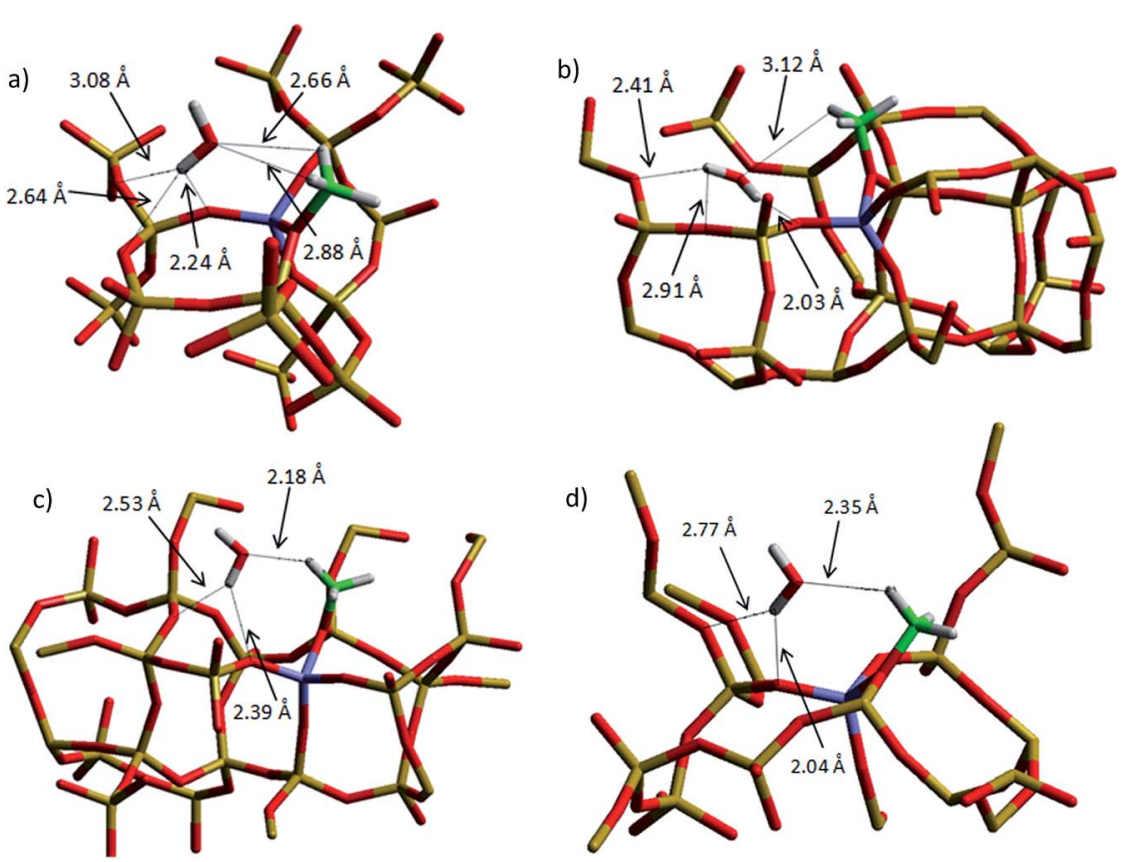

Fig. 13 Optimised geometries of the methoxylated structures of (a) HY (b) H-ZSM-5 (I2), (c) H-ZSM-5 (M7), and (d) H-ZSM-5 (Z6).

sites. Threefold coordination is also the case for the ZSM-5 (I2) system, which has the second most exothermic methoxylation energy, but for $\mathrm{H}-\mathrm{Y}$ the water molecule is also coordinated to two of the methyl hydrogens. The H-bonds associated with the H-Y system are not the shortest of all the configurations: the shortest is $2.24 \AA$, compared to $2.04 \AA$ in the ZSM-5 (Z6) system. However, the longer H-bonds in $\mathrm{H}-\mathrm{Y}$ are compensated by their increased quantity, thus highlighting the importance of highly coordinated structures in stabilising the system when considering the interaction of sorbates such as methanol with the active sites of acidic zeolite catalysts.

Using the QM/MM methodology we have, therefore, obtained new insights into the interaction, and reaction, of methanol with zeolite acidic sites and discussed how this may change with framework structure and aluminium location. Future work will use the embedded cluster models to investigate the barriers of methoxylation in zeolites using transition state searches. The effect of including multiple methanol molecules will also be investigated as the formation of $\mathrm{H}$ bonded networks reduces the total methoxylation barrier for the FER framework, ${ }^{49}$ thus further emphasising the importance of highly coordinated systems in controlling the barrier of such reactive processes.

\section{Summary and conclusions}

QM/MM methods clearly have a major role to play in the study of catalytic systems. Earlier work demonstrated their efficacy in modelling active sites in zeolites. Here, we investigated the energetics of deprotonation, methanol 
adsorption and methoxylation in two acidic zeolite catalysts. Embedded cluster systems have been used to model zeolites H-Y and H-ZSM-5, with acidic sites centred in the straight channel, sinusoidal channel and intersection region of the latter system. The hierarchy of deprotonation energies was calculated as $\mathrm{H}-\mathrm{Y}<\mathrm{H}-$ ZSM-5 (Z6) < H-ZSM-5 (I2) < H-ZSM-5 (M7). The side-on adsorption energy of methanol in each structure was also calculated, giving a trend of H-ZSM-5 (M7) < H-Y < H-ZSM-5 (I2) < H-ZSM-5 (Z6). The most favourable adsorption site, which was H-ZSM-5 (M7), exhibited an adsorbed geometry where two methyl hydrogens were able to hydrogen bond to framework oxygen atoms, suggesting that the $\mathrm{H}$ bonding behaviour of the methyl group may be dominant in controlling the adsorption energy. The methoxylation energy was calculated, giving a trend of $\mathrm{H}-\mathrm{Y}$ $<$ H-ZSM-5 (I2) < H-ZSM 5 (M7) < H-ZSM5-I2 (Z6). The ordering of our results suggests the total exothermicity of methoxylation is not dependent on the adsorption energy of methanol. However, the effect of increased framework coordination, including $\mathrm{H}$-bonding of methyl groups, was emphasised as the most coordinated system gave the lowest energy configuration, similar to our observations for methanol adsorption.

The present paper shows the role of the QM/MM modelling techniques in zeolite catalysis, as well as the limitations in using the deprotonation energy as a measure of catalytic reactivity for a material. We believe that QM/MM modelling in catalytic science can, however, be made much broader.

\section{Acknowledgements}

We are indebted to our early collaborator Judy To for her work on metal doped zeolites, reviewed in this paper, and ChemShell developers Paul Sherwood and Tom Keal for support with ChemShell calculations. Via our membership of the UK's HEC Materials Chemistry Consortium, which is funded by the EPSRC (EP/ L000202), this work used the ARCHER UK National Supercomputing Service (http://www.archer.ac.uk). The authors acknowledge further the use of the UCL Legion High Performance Computing Facility (Legion@UCL), and associated support services, in the completion of this work. The authors would like to acknowledge the Engineering and Physical Sciences Research Council, Grant No. EP/K014668/1 and Grant No. EP/G036675/1 for financial support under their Centres for Doctoral Training scheme, the STFC and the ISIS Pulsed Neutron and Muon Source for funding and sponsorship. AJL is grateful to the Ramsay Memorial Fund and UCL Chemistry for research fellowship funding. UK Catalysis Hub is kindly thanked for resources and support provided via our membership of the UK Catalysis Hub Consortium and funded by the EPSRC (grants EP/K014706/ 1, EP/K014668/1, EP/K014854/1 EP/K014714/1 and EP/M013219/1).

\section{References}

1 V. Van Speybroeck, K. Hemelsoet, L. Joos, M. Waroquier, R. G. Bell and C. R. A. Catlow, Chem. Soc. Rev., 2015, 44, 7044-7111.

2 S. P. Greatbanks, P. Sherwood and I. H. Hillier, J. Phys. Chem., 1994, 98, 81348139.

3 S. P. Greatbanks, P. Sherwood, I. H. Hillier, R. J. Hall, N. A. Burton and I. R. Gould, Chem. Phys. Lett., 1995, 234, 367-372. 
4 S. P. Greatbanks, I. H. Hillier, N. A. Burton and P. Sherwood, J. Chem. Phys., 1996, 105, 3770-3776.

5 P. Sherwood, A. H. de Vries, S. J. Collins, S. P. Greatbanks, N. A. Burton, M. A. Vincent and I. H. Hillier, Faraday Discuss., 1997, 106, 79-92.

6 S. P. Greatbanks, I. H. Hillier and P. Sherwood, J. Comput. Chem., 1997, 18, 562-568.

7 P. Sherwood, A. H. de Vries, M. F. Guest, G. Schreckenbach, C. R. A. Catlow, S. A. French, A. A. Sokol, S. T. Bromley, W. Thiel, A. J. Turner, S. Billeter, F. Terstegen, S. Thiel, J. Kendrick, S. C. Rogers, J. Casci, M. Watson, F. King, E. Karlsen, M. Sjøvoll, A. Fahmi, A. Schäfer and C. Lennartz, J. Mol. Struct.: THEOCHEM, 2003, 632, 1-28.

8 S. Metz, J. Kaestner, A. A. Sokol, T. W. Keal and P. Sherwood, Wiley Interdiscip. Rev.: Comput. Mol. Sci., 2014, 4, 101-110.

9 A. A. Sokol, S. T. Bromley, S. A. French, C. R. A. Catlow and P. Sherwood, Int. J. Quantum Chem., 2004, 99, 695-712.

10 D. Berger, A. J. Logsdail, H. Oberhofer, M. R. Farrow, C. R. A. Catlow, P. Sherwood, A. A. Sokol, V. Blum and K. Reuter, J. Chem. Phys., 2014, 141, 024105.

11 M. Sierka and a. Joachim Sauer, Faraday Discuss., 1997, 106, 41-62.

12 U. Eichler, M. Brandle and J. Sauer, J. Phys. Chem. B, 1997, 101, 10035-10050.

13 J. Sauer, U. Eichler, U. Meier, A. Schafer, M. von Arnim and R. Ahlrichs, Chem. Phys. Lett., 1999, 308, 147-154.

14 L. W. Chung, W. M. C. Sameera, R. Ramozzi, A. J. Page, M. Hatanaka, G. P. Petrova, T. V. Harris, X. Li, Z. F. Ke, F. Y. Liu, H. B. Li, L. N. Ding and K. Morokuma, Chem. Rev., 2015, 115, 5678-5796.

15 V. A. Nasluzov, E. A. Ivanova, A. M. Shor, G. N. Vayssilov, U. Birkenheuer and N. Rösch, J. Phys. Chem. B, 2003, 107, 2228.

16 E. A. Ivanova Shor, A. M. Shor, V. A. Nasluzov, G. N. Vayssilov and N. Rösch, J. Chem. Theory Comput., 2005, 1, 459-471.

17 A. S. Mysovsky, P. V. Sushko, S. Mukhopadhyay, A. H. Edwards and A. L. Shluger, Phys. Rev. B: Condens. Matter Mater. Phys., 2004, 69, 10.

18 A. H. Edwards, P. V. Sushko, A. L. Shluger and V. B. Sulimov, IEEE Trans. Nucl. Sci., 2002, 49, 1383-1388.

19 J. R. Hill and J. Sauer, J. Phys. Chem., 1994, 98, 1238-1244.

20 J. R. Hill and J. Sauer, J. Phys. Chem., 1995, 99, 9536-9550.

21 M. Taramasso, G. Perego and B. Notari, US Pat., 4410501, 1983.

22 S. Bordiga, A. Damin, G. Berlier, F. Bonino, G. Ricchiardi, A. Zecchina and C. Lamberti, Int. J. Mol. Sci., 2001, 2, 167.

23 S. A. French, A. A. Sokol, J. To, C. R. A. Catlow, N. S. Phala, G. Klatt and E. van Steen, Catal. Today, 2004, 93-5, 535-540.

24 J. To, P. Sherwood, A. A. Sokol, I. J. Bush, C. R. A. Catlow, H. J. J. van Dam, S. A. French and M. F. Guest, J. Mater. Chem., 2006, 16, 1919-1926.

25 J. To, A. A. Sokol, S. A. French, C. R. A. Catlow, P. Sherwood and H. J. J. van Dam, Angew. Chem., Int. Ed., 2006, 45, 1633-1638.

26 D. Gleeson, G. Sankar, C. R. A. Catlow, J. M. Thomas, G. Spano, S. Bordiga, A. Zecchina and C. Lamberti, Phys. Chem. Chem. Phys., 2000, 2, 4812-4817.

27 J. To, A. A. Sokol, S. A. French and C. R. A. Catlow, J. Phys. Chem. C, 2007, 111, 14720-14731. 
28 C. M. Barker, D. Gleeson, N. Kaltsoyannis, C. R. A. Catlow, G. Sankar and J. M. Thomas, Phys. Chem. Chem. Phys., 2002, 4, 1228-1240.

29 J. To, A. A. Sokol, S. A. French and C. R. A. Catlow, J. Phys. Chem. C, 2008, 112, 7173-7185.

30 V. N. Shetti, P. Manikandan, D. Srinivas and P. Ratnasamy, J. Catal., 2003, 216, 461-467.

31 C. D. Chang and A. J. Silvestri, J. Catal., 1977, 47, 249-259.

32 C. Maiden, Stud. Surf. Sci. Catal., 1988, 36, 1-16.

33 U. Olsbye, S. Svelle, M. Bjørgen, P. Beato, T. V. Janssens, F. Joensen, S. Bordiga and K. P. Lillerud, Angew. Chem., Int. Ed., 2012, 51, 5810-5831.

34 R. Shah, J. D. Gale and M. C. Payne, J. Phys. Chem., 1996, 100, 11688-11697.

35 S. R. Blaszkowski and R. A. van Santen, J. Phys. Chem. B, 1997, 101, 2292-2305.

36 P. E. Sinclair and C. R. A. Catlow, J. Chem. Soc., Faraday Trans., 1997, 93, 333345.

37 Z.-M. Cui, Q. Liu, S.-W. Bain, Z. Ma and W.-G. Song, J. Phys. Chem. C, 2008, 112, 2685-2688.

38 A. J. O'Malley, S. F. Parker, A. Chutia, M. R. Farrow, I. P. Silverwood, V. GarcíaSakai and C. R. A. Catlow, Chem. Commun., 2016, 52, 2897-2900.

39 D. Lesthaeghe, V. Van Speybroeck, G. B. Marin and M. Waroquier, Ind. Eng. Chem. Res., 2007, 46, 8832-8838.

40 K. Hemelsoet, J. Van der Mynsbrugge, K. De Wispelaere, M. Waroquier and V. Van Speybroeck, ChemPhysChem, 2013, 14, 1526-1545.

41 R. Vetrivel, C. Catlow and E. Colbourn, J. Phys. Chem., 1989, 93, 4594-4598.

42 J. Gale, C. Catlow and J. Carruthers, Chem. Phys. Lett., 1993, 216, 155-161.

43 C. Zicovich-Wilson, P. Viruela and A. Corma, J. Phys. Chem., 1995, 99, 1322413231.

44 P. Sinclair and C. Catlow, J. Chem. Soc., Faraday Trans., 1996, 92, 2099-2105.

45 S. R. Blaszkowski and R. A. van Santen, J. Am. Chem. Soc., 1996, 118, 51525153.

46 S. Blaszkowski and R. Van Santen, J. Phys. Chem., 1995, 99, 11728-11738.

47 J. Gale, R. Shah, M. Payne, I. Stich and K. Terakura, Catal. Today, 1999, 50, 525532.

48 F. Haase, J. Sauer and J. Hutter, Chem. Phys. Lett., 1997, 266, 397-402.

49 J. Andzelm, N. Govind, G. Fitzgerald and A. Maiti, Int. J. Quantum Chem., 2003, 91, 467-473.

50 D. Berger, A. J. Logsdail, H. Oberhofer, M. R. Farrow, C. R. A. Catlow, P. Sherwood, A. A. Sokol, V. Blum and K. Reuter, J. Chem. Phys., 2014, 141, 024105.

51 G. Artioli, C. Lamberti and G. Marra, Acta Crystallogr., Sect. B: Struct. Sci., 2000, 56, 2-10.

52 J. Hriljac, M. Eddy, A. Cheetham, J. Donohue and G. Ray, J. Solid State Chem., 1993, 106, 66-72.

53 P. Sherwood, A. H. de Vries, M. F. Guest, G. Schreckenbach, C. R. A. Catlow, S. A. French, A. A. Sokol, S. T. Bromley, W. Thiel and A. J. Turner, J. Mol. Struct.: THEOCHEM, 2003, 632, 1-28.

54 D. Nachtigallova, P. Nachtigall and O. Bludský, Phys. Chem. Chem. Phys., 2004, 6, 5580-5587.

55 R. Ahlrichs and P. Taylor, J. Chim. Phys. Phys.-Chim. Biol., 1981, 78, 315-324. 
56 J. P. Perdew and Y. Wang, Phys. Rev. B: Condens. Matter Mater. Phys., 1992, 45, 13244.

57 A. D. Becke, J. Chem. Phys., 1993, 98, 5648-5652.

58 C. Lee, W. Yang and R. G. Parr, Phys. Rev. B: Condens. Matter Mater. Phys., 1988, 37, 785.

59 S. Vosko, L. Wilk and M. Nusair, Can. J. Phys., 1980, 58, 1200-1211.

60 P. Stephens, F. Devlin, C. Chabalowski and M. J. Frisch, J. Phys. Chem., 1994, 98, 11623-11627.

61 P. J. Wilson, T. J. Bradley and D. J. Tozer, J. Chem. Phys., 2001, 115, 9233-9242.

62 M. F. Guest, I. J. Bush, H. J. Van Dam, P. Sherwood, J. M. Thomas, J. H. Van Lenthe, R. W. Havenith and J. Kendrick, Mol. Phys., 2005, 103, 719-747.

63 W. Smith, C. Yong and P. Rodger, Mol. Simul., 2002, 28, 385-471.

64 C. Broyden, Math. Comput., 1970, 24, 365-382.

65 R. Fletcher, Comput. J., 1970, 13, 317-322.

66 D. Goldfarb, Math. Comput., 1970, 24, 23-26.

67 D. F. Shanno, Math. Comput., 1970, 24, 647-656.

68 W. Mortier, J. Sauer, J. Lercher and H. Noller, J. Phys. Chem., 1984, 88, 905-912. 69 J. Sauer, J. Mol. Catal., 1989, 54, 312-323.

70 F. Haase and J. Sauer, Microporous Mesoporous Mater., 2000, 35, 379-385.

71 W. Jost, J. Chem. Phys., 1933, 1, 466-475.

72 M. Sierka, U. Eichler, J. Datka and J. Sauer, J. Phys. Chem. B, 1998, 102, 63976404.

73 A. J. Jones and E. Iglesia, ACS Catal., 2015, 5, 5741-5755.

74 S. F. Boys and F. d. Bernardi, Mol. Phys., 1970, 19, 553-566.

75 S. Svelle, C. Tuma, X. Rozanska, T. Kerber and J. Sauer, J. Am. Chem. Soc., 2008, 131, 816. 